\title{
Development Research on Internet Cultural Industry in Hebei Province under the Network Technology
}

\author{
Xuguang Yang \\ Environmental Management College of China, Qinhuangdao, 066102, P.R, China \\ 1162054997@qq.com
}

Keywords: Network technology, Internet +, Cultural industry, Technological integration

\begin{abstract}
With the rapid development of network information technology, the traditional cultural industry is growing stronger with the support of Internet technology. In this context, around the sharing of the network information platform, the cultivation of emerging industries and the information security, the cultural industry in Hebei province has strengthened the collaborative development of network economy and real economy of Internet technology and cultural industry by using the Internet thinking and Internet technology with the deep integration of informatization and cultural industry as the main line. It has helped the cultural industry gradually get rid of the shackles of the traditional development model and move towards the new stage of mutual promotion and deep integration with the Internet.
\end{abstract}

\section{Introduction}

As the Second World Internet Conference held in Wuzhen, the new trend of the combination of network technology and a variety of industries in the information age has brought a new era for the cultural industry in Hebei province. As an important engine to promote the development of cultural industry, Internet information technology has brought new opportunities for the development of cultural industry through a high integration of the information technology industry and the cultural industry. With the support of "Internet +" big data, traditional cultural industry in Hebei has started to enter an era of the "Internet + culture industry". The transformation, upgrading and updating of the industry, the formation of a new cultural industry ecosystem have provided economic development of Hebei's overall cultural industry with an important driving force.

\section{Basic situation of Internet information technology and cultural industry}

In recent years, the "Internet + culture" has provided unprecedented opportunities for Hebei's cultural industry. The cultural industry has been ranked the first among Hebei's new dominant industrial system. Based on the development of the traditional cultural industry, the new cultural industries like the animation industry, online games, e-books, digital publishing also have made progress, which have been the growing point of Hebei's cultural industry development and construction of cultural strong province. Especially the integrated development of the traditional media industry, network technology and digital technologies has not only changed the models and methods of traditional news publishing, realized the technological innovation, product innovation and market innovation, but also has promoted the emergence of a large number of new media and digital publishing companies. For example, Hebei Daily, Hebei Youth Daily, Hebei Education and other traditional publishing units have transformed to the to digital direction increasingly. Hebei Guanlin Digital Publishing Co., Ltd. as well as Fang Yuan Audio and Video Electronic Publishing Co., Ltd. are developing prosperously with the help of scientific and technological strength. From the the current development trend of Hebei's digital publishing, it can be seen that digital publishing has had a profound impact on the structure of traditional publishing and media industry. It has broken the traditional boundaries of time and space (as shown in Table 1), and has become the new growing point and strong driving force of Hebei's economic development. To 2015, Hebei 
provincial government has adopted a series of measures to promote the development of digital publishing industry, strongly supporting the development of digital publishing industry respectively from the integration of development resources, the construction of key projects, the improvement of international exchanges and the protection of intellectual property protection.

Table1. Comparison of characteristics of traditional publishing industry and digital publishing industry

\begin{tabular}{|c|c|c|}
\hline & Traditional publishing industry & Digital publishing industry \\
\hline $\begin{array}{c}\text { Industrial } \\
\text { characteristics }\end{array}$ & $\begin{array}{c}\text { Scale economies } \\
\text { Specialization of specific product } \\
\text { Standardization } \\
20 \% \text { to } 80 \% \text { profit principle }\end{array}$ & $\begin{array}{c}\text { Scope economy } \\
\text { Strategic expansion } \\
\text { Multiple directions and } \\
\text { diversification } \\
\text { Long Tail profit principle }\end{array}$ \\
\hline $\begin{array}{c}\text { Characteristics } \\
\text { of production } \\
\text { and } \\
\text { management }\end{array}$ & $\begin{array}{c}\text { Centralization } \\
\text { Smoothly undergoing } \\
\text { Large-scale standard product design } \\
\text { Low rate changes, high stability } \\
\text { Inventory management } \\
\text { Strengthening the concept of } \\
\text { hierarchical organization }\end{array}$ & $\begin{array}{c}\text { Networking } \\
\text { Unfixed operation } \\
\text { A large number of customized } \\
\text { products } \\
\text { Innovation and strong reaction } \\
\text { On-demand production } \\
\text { Organizational form of functional } \\
\text { modules }\end{array}$ \\
\hline
\end{tabular}

In order to create an atmosphere of th Internet + cultural industries ration of Internet + cultural industries, Hebei’s provincial government has issued Hebei Cultural Industry Promotion Plan. Its key task is to develop new cultural formats by using the digital, Internet and other high-techs, which has vigorously promoted the upgrading of cultural industries. It has set up comprehensive public service supporting platforms with diversified business such as Langfang public cultural service digital platform, Shijiazhuang national animation industry base business incubator-animation industry public technology platform, E-commerce platform of China bone-china industry supply chain, Hebei B2B e-commerce trading platform. These platforms have played a positive role in promoting the cultivation, content creation, technical training and industry consulting of Hebei's cultural industry projects. By 2015, Hebei has identified 56 industrial parks with high-tech cultures (number distribution shown in Figure 1). These creative industries with technological integration have laid a good foundation for the development of Internet culture industry. For example: Shijiazhuang Information Industry Base, Baoding Animation Industrial Park, Zhuozhou Studio City, Tangshan Ceramic Cultural and Creative Industry Park, Cultural Industry Park of Shijiazhuang Publishing Group, Hebei Digital Printing Industry Park. These high-tech-based cultural industries have realized the organic combination of culture, technology, products and markets with the cultural creativity and Internet technology as the core and the cultural creativity and Internet technology as the core to digital content, intellectual property rights as the subject. They have become the main support of the development and dissemination of Hebei's cultural industry. According to Hebei Bureau of Statistics, in 2012, the province's cultural industry increased 72.63 billion yuan, 18.88 billion yuan more than last year, with an increase of $35.1 \%$. The increase of cultural industry accounted for 2.73\% of GDP; in 2013, the province's cultural industry increased 95 billion yuan, accounting for 3.25\% of GDP; in 2014, Hebei's cultural industry increased 112 billion yuan, with an increase of about 20\%t, accounting for about 3.75\% of GDP. Hebei's cultural industry has been developed rapidly and made a series of fruitful results. Its integration with Internet technology continues to be deepened and the industrial structure is being constantly optimized, which has broadened the industrial chain and development of traditional culture, becoming the new engine to drive Hebei's economic growth. 


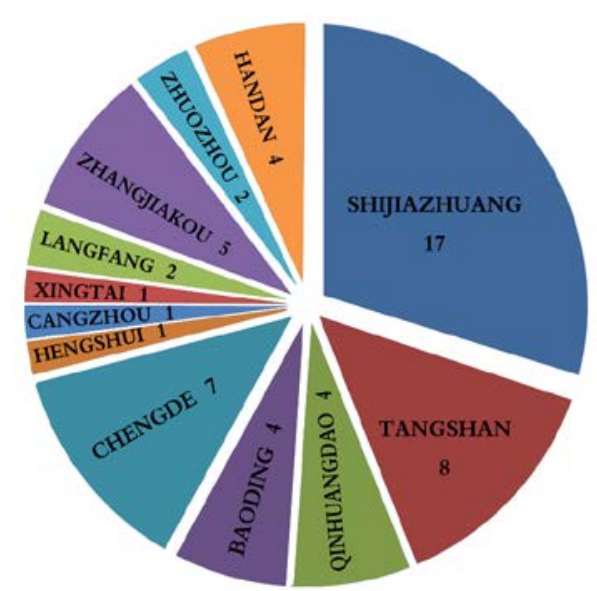

Fig.1 Diagram of Internet + cultural industries’

distribution numbers in cities

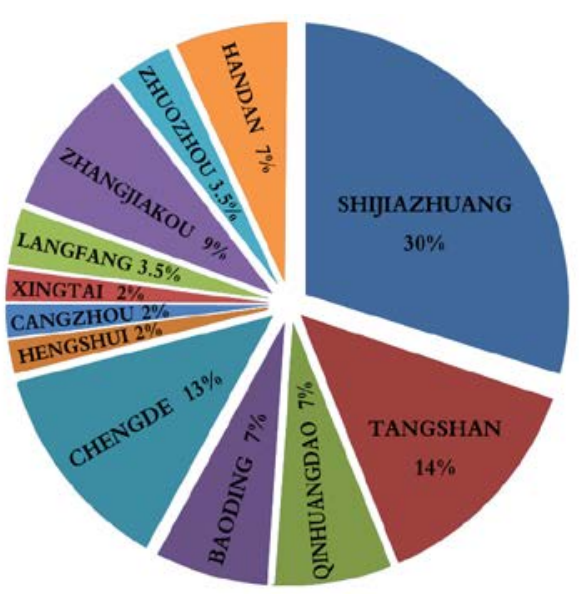

Fig.2 Diagram of the province’s

Internet + cultural industry distribution ratio

\section{Existing problems of the integration of Internet technology and cultural industries and reasons}

As the integration of cultural industry and Internet technology is still at the early stages of its development, there are still some inevitable problems in the good trend shown by the development of Hebei's cultural industry and the formation of some emerging cultural formats in the process of development. The most notable one is the uneven development of the Internet industry in regions. Judging from the Hebei's regional distribution ratio of cultural industry (Figure 2), we can find that the Internet culture industries in Shijiazhuang, Tangshan, Chengde, Qinhuangdao, Baoding, Zhangjiakou develop rapidly, among which, the scale of culture industry developed in Shijiazhuang accounted for $30 \%$ of Hebei's cultural industry units. There are many types of mixed cultural and creative industrial parks and industrial compositions, which account for around half of Hebei's entire cultural industry. The animation industry, cultural and creative industries and software development industry are particularly famous. Although the construction of cultural and creative industrial parks are increasing year by year, the proportion of arts and culture industry output are reducing, showing an imbalances in industrial development. Hebei has taken various measures to strengthen the construction of digital culture and technology like museums, galleries and libraries. The numbers of Internet exhibitions and online sales activities are also gradually increased. However, parts of traditional cultural formats haven't been integrated with the Internet technology yet. Those formats which have been integrated with the Internet technology also don't have ideal effects due to the low degree of integration. They haven't played the huge potentials of the integration of cultural industries and Internet technology. Specifically, the items are as follows: 1. Digital libraries have not reached the optimal integration and promotion yet. Library websites in Hebei basically have bibliographic search and consulting services. People have no access to literature information, statistics, research and reference, video lectures, audio resources. 2 . Mobile newspaper is maintained only by subscription fees. There are no profit points of value-added services. 3. In the related industries of radio and television, most functions like TV shopping, network management, e-commerce sites have not been effectively developed except the advertising. There are large blank spaces uninvolved. In this case, the Internet resources can't effectively be used. So it can not inspire a high-level cultural consumer demands, which greatly reduces the Internet scale effect and the industry's own market competitiveness.

In addition to the phenomenon above, there are another three reasons affecting the uneven development of Internet technology and cultural industry. Firstly, the economic efficiency and profitability of new cultural industries are generally higher than those of traditional cultural industries. With the same capital investment, emerging cultural industries like animation and online games have closer integration with Internet technology and the industries can generate 
more revenue. They have a relatively strong GDP contribution capacity, which makes cultural enterprises and the government have increased the investment and supports. For the traditional cultural industries with a relatively lower economic efficiency, they are easy to be overlooked when GDP is the main economic measure, which makes the cultural industries difficult to connect with the Internet industry. Secondly, the current Internet industries are in the form of large enterprises while the cultural industries are mostly the combination of small enterprises. The Internet industries despise the small scale of cultural industries while the cultural industries consider the Internet industries to be unattainable and hard to cooperate with. It has been a major obstacle to the balanced development of cultural and creative industries. Thirdly, for some cultural enterprises with high cultural values, the intellectual property rights are the driving force and lifeline of own survival and development. Hence, they tend to focus on how to protect intellectual property rights while ignoring the mutual sharing of industrial resources and creative products with massive users on the Internet platform, which makes the promotion of cultural products single with low scientific and technological content. The industrial growth rate has a significantly downward trend and the industry's growth is also declining. The insufficient connection of the Internet platform and industry information has become the bottleneck restricting the regional cultural industries and the economic development, affecting the healthy development of the industry.

For the "weak, small, scattered" problems of Hebei's overall development of cultural industries above, as well as the current situation that some SMEs can't effectively integrated with Internet technology, Hebei Cultural Industry Association can strengthen the cooperation with network operators to maximize the concentration of Internet technology resources and cultural resources. The Association can specially establish the network service platforms which integrate the cultural industry and technology, actively taking a series of measures to promote the development of Internet + cultural industries in Hebei in terms of the industry dynamics, supportive policies, the integration of development resources, the construction of key projects, the improvement of international exchanges and the protection of intellectual property rights, sparing no efforts in providing professional services and guidance for Hebei's science and technology parks of culture industries and cultural enterprises, helping solve problems met by different-scale cultural enterprises during the development and providing solutions. It will promote the development of the cultural industry in Hebei

\section{Conclusions}

Hebei's Internet culture industry started late. With the government's strong support, it has made considerable progress. However, there are still many problems including unbalanced industrial development, weak strength, low industrial integration and lack of regional advantages. After analyzing the specific issues presented by the current Internet industry and the cultural industry, further research on the constraints of the problems mentioned above will be made to find out the general idea, direction of development of Internet culture industry in Hebei scientifically and clearly so as to seek out the suitable development path of Hebei’s cultural industry.

\section{Acknowledgements}

Project topics: Hebei Science and Technology Department of Science and Technology Plan 2015 annual self-financing project in Hebei Province.Item Number:15456251

\section{References}

[1] S.F. Chen: Cultural Industries Need the Integration of Technology and Management, New Year Speech on the Twelfth China's Cultural Industry Forum (2015-01-10) http://www.fici.org.cn/twelfth/Index.html

[2] S.F. Chen,H.Wang and J.P.Wang: Chinese Internet Culture Industry Report in 2015, [M], 
Sino-Culture Press, 2015

[3] Chinese Art and Science Technology Research Institute, Integration of Culture, Technology and Mmajor Policies, [M], Red Flag Press, 2013

[4] Creative and Cultural Industries Times in China, http://www.ccitimes.com/diqu.php

[5] Z.Meng, Current Situation and Countermeasures of the Development of Cultural Industries in Hebei Province, Journal of Hebei University, [J], 2014 